\title{
SAÚDE MENTAL E A VISÃO ANTROPOLÓGICA: uma abordagem dos transtornos psíquicos sob o enfoque cultural
}

\author{
Mariana Albernaz Pinheiro de CARVALHO ${ }^{1}$ \\ Samilla Gonçalves de MOURA ${ }^{2}$ \\ Lawrencita Limeira ESPÍNOLA ${ }^{3}$ \\ Maria de Oliveira FERREIRA FILHA ${ }^{4}$
}

\begin{abstract}
${ }^{1}$ Enfermeira. Mestre em Enfermagem pela Universidade Federal da Paraíba. Docente da Universidade Federal de Campina Grande. Membro do Grupo de Estudos e Pesquisas em Saúde Mental Comunitária. E-mail: mary_albernaz@hotmail.com;
\end{abstract}

${ }^{2}$ Enfermeira. Mestranda do Programa de Pós-Graduação em Enfermagem. . Membro do Grupo de Estudos e Pesquisas em Saúde Mental Comunitária. E-mail: samilla_1988@hotmail.com;

${ }^{3}$ Psicóloga. Mestre em Enfermagem pela Universidade Federal da Paraíba. Docente da Universidade Federal de Campina Grande. Membro do Grupo de Estudos e Pesquisas em Saúde Mental Comunitária. E-mail: lawrencita_@hotmail.com;

${ }^{4}$ Enfermeira. Doutora em Enfermagem. Professora adjunto do Centro de Ciências da Saúde da Universidade Federal da Paraíba. Líder do Grupo de Estudos e Pesquisas em Saúde Mental Comunitária. E-mail: marfilha@ yahoo.com.br.

\section{Recebido em: 21/05/2013 - Aprovado em: 30/07/2013 - Disponibilizado em: 15/08/2013}

\section{RESUMO}

O presente estudo objetiva destacar a relação entre influência cultural e surgimento de transtornos psíquicos. Trata-se de uma revisão integrativa, subsidiada por um levantamento de periódicos na Biblioteca Virtual em Saúde nos meses de junho, julho e agosto de 2011. Realizou-se um levantamento de periódicos no portal da Bireme - BVS (Biblioteca Virtual em Saúde) nos meses de junho, julho e agosto de 2011, incluindo as bases de dados LILACS e SCIELO. A desigualdade, o preconceito e a exclusão manifestam-se em fenômenos, como violência, discriminação e adoecimento mental. Sintomas psíquicos estão fortemente associados a uma pressão cultural exercida socialmente, considerando que variáveis capitalistas influenciam as formas pelas quais os indivíduos se enxergam em uma realidade onde o valor individual associa-se ao poder financeiro. Os transtornos psíquicos vêm, portanto, assumindo um importante papel social, contemplando a supervalorização do ter como consequência de exigências culturais, favorecendo a adoção de comportamentos desencadeantes de sintomas biológicos, sobretudo sintomas psíquicos.

Palavras-chave: Saúde mental. Cultura. Antropologia cultural. Sintomas psíquicos.

\section{ABSTRACT}

The present study aims to highlight the relationship between cultural influence and the emergence of mental disorders. It is an integrative review, subsidized by a periodic survey of the Virtual Health Library in the months of June, July and 
August 2011. We conducted a periodic survey of the portal Bireme - VHL (Virtual Health Library) in the months of June, July and August 2011, including the databases LILACS and SciELO. The increasing, the prejudice and the exclusion take place through phenomenon such as violence, discrimination and the mental illness. The psycho symptoms are strongly related to cultural and standard pressure made by society, considering that capitalist variables has been influenced ways that individuals see each other in a reality in which the individual worth are related to a financial power. The refore psychological disorders have been taking an important social role, contemplating the overvaluation of the have and not be as consequence of that need on the actual circumstances; circumstances that has been chosen the adoption of behaviors reflected in biological symptoms, especially psychological symptoms.

Keywords: Mental Health. Culture. Cultural Anthropology. Psychological Symptoms.

\section{INTRODUÇÃO}

Falar sobre influência cultural é como adentrar um estudo detalhado da vida de cada ser humano, tendo em vista a influência que a cultura e a sociedade têm na sua personalidade e no seu modo de viver.

As culturas são desenvolvidas por grupos sociais, desde o surgimento de sua história, na construção de suas formas de subsistência, na organização da vida social e política, nas relações com o meio e com os outros grupos, na produção de conhecimentos, nas atitudes a serem tomadas, enfim, na vida cotidiana como um todo.

Visto que o Brasil é um país multirracial e pluriétnico, isso implica a existência de diversidade ou pluralidade cultural, muito embora exista uma enorme dificuldade de reconhecimento dessa diversificação por parte de muitos brasileiros.

Sabe-se que fatores culturais e históricos, juntamente com os biológicos e ambientais, contribuem para a produção dos comportamentos psicossociais, e que cada sociedade elabora suas próprias distinções em relação aos padrões de normalidade, desvio e anormalidade. É, portanto, da interação dialética entre história, cultura e biologia que surgem as bases para a compreensão do campo da saúde mental.

No mundo contemporâneo, cada vez mais a sociedade tem sido vítima de transformações e influências oriundas das mais diversas culturas e hábitos que estão arraigados no comportamento ou na própria personalidade humana. Dessa forma, o espírito de competitividade, o crescimento do capitalismo, a crescente urbanização e o avanço tecnológico têm contribuído sobremaneira para determinar o que é "bom ou ruim" e "normal ou anormal", ou seja, o que melhor se enquadra nos padrões impostos socialmente é visto de maneira mais aceitável.

Para se viver democraticamente em uma sociedade plural, é preciso respeitar os diferentes grupos e culturas que a constituem. 
Sabe-se que as regiões brasileiras têm características culturais bastante diversas, e que a convivência entre grupos diferenciados nos planos sociais e culturais muitas vezes é marcada pelo preconceito e pela discriminação.

Assim a carência de espaços abertos à liberdade de expressão, a valorização do "ter" em detrimento do "ser" e o preconceito social e cultural têm tornado pessoas e comunidades cada vez mais vulneráveis aos transtornos psíquicos, reforçando os altos índices de pessoas acometidas mentalmente.

A cultura também influencia na forma como se expressa o sofrimento psíquico. No mundo hodierno, a sociedade tem se defrontado desde o final o século XX com a cultura do vazio. Apesar de a modernidade ter proporcionado muitos avanços tecnológicos e científicos, o "homem moderno" tornou-se mais frágil diante de seus conflitos internos. $\mathrm{O}$ sofrimento psíquico passou a ter diferentes faces: pessoas com transtornos da personalidade, distúrbios alimentares e o uso abusivo de álcool e drogas são representantes da dor psíquica na cultura ocidental. Os indivíduos com esses quadros psicopatológicos buscam em comportamentos automutilantes, na comida ou nas drogas uma forma de evitar sentir as emoções que se manifestam sob a forma de sentidos negativos.

A Antropologia considera que a saúde e o que se relaciona a ela são fenômenos culturalmente construídos e culturalmente interpretados, uma vez que as pessoas não apenas sofrem de doenças, mas também de perturbações fortes vivenciadas ao longo de suas vidas.

Essa abordagem abre um horizonte para além do modelo biomédico, possibilitando analisar e identificar como os fatores sociais e culturais constroem o pensar e o agir frente à saúde e à doença.

Ante o exposto, verifica-se a necessidade de aprofundar conhecimentos acerca das repercussões trazidas pela cultura enquanto elemento impositor de ditames na perspectiva da influência e normalização social, visto que tais fatores têm exercido forte participação no contexto do adoecimento mental.

Partindo desses pressupostos, o presente estudo objetiva destacar, com base na literatura, a relação entre influência cultural e o surgimento de transtornos psíquicos na sociedade.

\section{METODOLOGIA}

Trata-se de uma revisão integrativa da literatura, que é uma forma de investigar estudos já existentes, visando obter conclusões a respeito de um tópico em particular (BEYEA; NICOLL, 1998). Constitui-se em uma estratégia utilizada para identificar as evidências existentes, 
embasando e consolidando a prática de saúde nas mais distintas temáticas.

Realizou-se um levantamento de periódicos no portal da Bireme - BVS (Biblioteca Virtual em Saúde) nos meses de junho, julho e agosto de 2011, incluindo as bases de dados LILACS e SCIELO. Utilizouse o português como idioma preferencial. Foram explorados apenas artigos apresentados no formato de texto integral.

Para a localização dos estudos, foram utilizados os descritores "saúde mental", “cultura", "antropologia cultural”, "sintomas psíquicos" e outros pertinentes à temática, de modo a se obter fundamentação acerca da problemática investigada.

\section{DISCUSSÃO}

\section{A cultura enquanto elemento de identidade}

Cultura pode ser definida como um conjunto de elementos que mediam e qualificam qualquer atividade física ou mental que não seja determinada pela biologia, e que seja compartilhada por diferentes membros de um grupo social. Trata-se de elementos sobre os quais os atores sociais constroem significados para as ações e interações sociais concretas e temporais, assim como sustentam as formas sociais vigentes, as instituições e seus modelos operativos. A cultura inclui valores, símbolos, normas e práticas (LANGDON; WIIK, 2010).

A cultura exerce grande influência em todos os aspectos da vida das pessoas, incluindo suas crenças, comportamentos, percepções, emoções, religião, estrutura familiar, linguagem, alimentação, vestuário, imagem corporal, dentre outras situações. A cultura pode ser definida também como um conjunto de teias e significados que o próprio homem teceu e na qual se encontra amarrado. Constitui-se no conjunto de mecanismos de controle que governam o comportamento humano. Isso demonstra o quanto a cultura influencia os diversos aspectos da vida humana, e que esses aspectos são produzidos pelo próprio homem, no decorrer de sua vida e de suas experiências (GEERTZ, 1989).

Ao se afirmar que a cultura é aprendida, compartilhada e padronizada profere-se que não se explica as diferenças do comportamento humano através da biologia de forma isolada. Dessa forma, a biologia oferece um pano de fundo para $o$ comportamento, assim como fornece as potencialidades da formação e desenvolvimento humano. Porém, é a cultura compartilhada pelos indivíduos formadores de uma sociedade que torna essas potencialidades em atividades específicas, diferenciadas e simbolicamente inteligíveis e comunicáveis, estabelecendo "padrões de normalidade" (ROBERTSON, 2000). 
A cultura é compartilhada e padronizada, pois consiste em uma criação humana, partilhada por grupos sociais específicos. As formas materiais, os conteúdos e atribuições simbólicas a ela atreladas são padronizados a partir de interações sociais concretas dos indivíduos, assim como resultante de sua experiência em determinados contextos e espaços específicos, os quais podem ser transformados, permeados e compartilhados por diferentes segmentos sociais. Embora o conteúdo e formas inerentes a cada cultura possam ser apreendidos e replicados individualmente - conferindo à cultura caráter de experiência pessoal internalizada e incorporada - concerne à antropologia: a) identificar os padrões culturais repartidos pelos coletivos de indivíduos; b) inferir sobre o que há em comum nas ações, atribuições de sentido, significados e simbolismo projetados pelos indivíduos sobre o mundo material e natural e c) ponderar sobre a experiência de viver em sociedade, sobre adoecer e se cuidar, definindo-a como experiência eminentemente intersubjetiva e relacional, mediada pelo fenômeno cultural (LANGDON; WIIK, 2010).

Estudiosos da Antropologia apresentam outra dimensão de cultura: aquela que rejeita a visão coesa e unificadora, baseada no paradigma de unidade cultural e de sociedade unitária, padronizada e integrada, que avança em perspectiva fluida e aponta para a fragmentação do todo, para a desordem, para a particularidade, para o pluralismo, para o sincretismo, para a heterogeneidade, para a complexidade e para a diversidade cultural (ROBERTSON, 2000).

O mesmo autor ainda expõe a descontinuidade e as diferenças que devem ser mostradas nos trabalhos que trazem uma abordagem cultural, possibilitando a expressão de divergências. Valorizam o indivíduo como sujeito de sua própria vivência e a contextualização na análise do estudo, promovendo um olhar dinâmico, progressivo, que admite contestação e rupturas nos trabalhos.

Isso significa entender a cultura numa nova ordem global, vale dizer, de forma mais ampla, dando espaço para as diferenças, inclusive para as antagônicas, expressarem-se num mesmo tempo e lugar. Denota opor-se à rigidez, ao reducionismo, à limitação que a própria estética da vida pode querer impor. Mostra aceitar uma composição cultural múltipla, oriunda de diferentes modelos de vida social, que podem trazer conflitos, e não harmonia na existência comum. Significa ainda uma fusão de diferentes elementos culturais, mantendo a natureza original de cada um (FEATHERSTONE, 1997).

Por outro lado, a cultura não pode ser avaliada isoladamente, mas como um dos componentes de uma mistura complexa de influências que atuam na vida das pessoas. Influências estas herdadas pelos indivíduos 
na sociedade em que vivem e que evidenciam as formas pelas quais veem o mundo e se relacionam com as outras pessoas de seu meio (BUDO, 2007).

\section{Contemporaneidade e adoecimento mental:} as influências da cultura moderna na saúde da população

O crescimento cada vez mais intenso do processo de modernização tem acarretado mudanças preponderantes no cotidiano das pessoas. Se por um lado se verificava amplo acesso aos bens e serviços produzidos pelos setores sociais, por outro, identifica-se que a desigualdade e a exclusão estão cada vez mais evidentes nas sociedades mercadistas atuais. A crescente desigualdade, o preconceito e a exclusão social manifestam-se através de fenômenos como a violência, miséria, discriminação, desemprego, entre outros, e também no processo de adoecimento mental (SANTOS, 1999).

Esse processo é marcado por situações de sofrimento que muitas vezes, somente é percebido pelo desencadeamento de sintomas físicos e corporais, manifestados pelo estresse constante, intolerância, ansiedade elevada e sinais de angústia crescente, levando as pessoas a buscarem serviços de saúde, na certeza de encontrar medicamentos para alívio de seu sofrimento (FERREIRA FILHA et al, 2009).
A atual estrutura de organização da sociedade é decisiva para a saúde mental de seus integrantes. $\mathrm{O}$ meio social influencia os indivíduos, ao fornecer modelos de estruturação e formação da personalidade; e a subjetividade dos mesmos é estruturada de acordo com tais modelos: suas necessidades e anseios estão atrelados aos moldes preexistentes. Aqueles que não conseguem se enquadrar às demanda dos ideais vigentes pela cultura são marginalizados e considerados anormais e/ou em quadros patológicos (GUNSBERG, 2001).

Em se tratando de questões psíquicas, o segmento social apresenta regras a ele inerentes: condições e requisitos introjetados pelos indivíduos por meio da dimensão de sua personalidade, denominada superego. Nessa dimensão o indivíduo assume os encargos de auto-observação, de moralidade e a função de ideal (o modelo ao qual o sujeito procura moldar-se). Portanto, o superego é constructo da cultura, referente à sociedade em que está inserido o indivíduo (LAPLANCHE, 1983).

Como dito anteriormente, os indivíduos que não portam as qualidades exigidas pelos ideais da cultura são excluídos. $\mathrm{Na}$ cultura neoliberal, as pessoas são culpabilizadas por não possuírem as capacidades requeridas pelo modelo neoliberal, como, por exemplo, autossuficiência e identidade flutuante. Mesmo que esse ideal de homem seja 
inatingível, toda a responsabilidade por não se adequar àquele modelo recai sobre o indivíduo (MAIA, 2001).

A identidade das pessoas se encontra em crise, pois elas não sabem mais quem são, isso porque o que sabem só é possível quando sabem de seu mundo e o dos outros. Nessa crise, surgem os mal-estares, tais como os sentimentos de vacuidade, tristeza, exclusão ou até melancolia, todos esses sintomas embutidos com o mesmo rótulo: depressão e perda da autonomia pessoal (MONTEIRO, 2004).

Os indivíduos, vítimas do jogo do "cada um por si" e "que vença o melhor", perdem o que lhes servia de apoio: perda de seus próximos, do afeto de seus entes, que se tornam obstáculos à satisfação pessoal; e perda de um Estado, que os deixa à mercê de sua própria sorte, regido pelo mecanismo impessoal do mercado. A disparidade e a competitividade entre os indivíduos são vistas como naturais e necessárias no modelo neoliberal, determinando grandes limitações no curso da vida. A insatisfação com a realidade, que exige muitos sacrifícios dos indivíduos, caracteriza-se como um dos fatores que favorecem e desencadeiam o adoecimento mental (FENICHEL, 1981).

$O$ ideal de homem requerido pela sociedade contemporânea é questão longe da realidade dos indivíduos, ou mesmo inalcançável. Para o primeiro autor, esse fator aumenta a incidência de sintomas psíquicos, tanto nas classes médias quanto nas menos privilegiadas. Nas classes médias, o desejo não é satisfeito plenamente, é inesgotável, posto que não existe nada fixo: tudo é temporário, instantâneo; em se tratando de consumo, por exemplo, sempre existem produtos novos lançados no mercado, cada um superando o anterior em alguma inovação. Já as classes mais baixas, que não têm possibilidade, não têm acesso aos ideais de consumo da cultura, acabam ficando à margem da sociedade, ou seja, são excluídas. Percebe-se, dessa forma, que a tirania capitalista se caracteriza como um sistema gerador de insatisfação nas pessoas para com o seu "eu" e, sobretudo, para com os demais (GUINSBERG, 2001).

Portanto, os sintomas psíquicos estão sendo cada vez mais associados à "pressão padronizável" exercida pela sociedade, tendo em vista que variáveis mercadológicas têm influenciado sobremaneira as formas pelas quais os indivíduos se enxergam e enxergam os outros dentro de uma realidade onde o valor individual das pessoas está fortemente associado ao estigma financeiro e ao poder de pertencimento.

\section{CONSIDERAÇÕES FINAIS}

A cultura é um dos mais fortes elementos constituintes da identidade humana, de tal forma que passa a determinar valores e critérios de inclusão e/ou exclusão 
que perpassam as concepções individuais das pessoas. O peso arraigado na cultura oferece sérios riscos sociais frente ao desenvolvimento tecnológico, ao capitalismo financeiro e à liberdade de expressão que exercem influência no processo de socialização e inclusão social dos indivíduos, contribuindo para os altos índices de transtornos psíquicos na contemporaneidade.

Os transtornos psíquicos vêm assumindo um importante papel na sociedade, tendo em vista a supervalorização do ter e não do ser como consequência, essa exigência da conjuntura atual tem favorecido o surgimento e a adoção de comportamentos que se refletem no aparecimento de sintomas patológicos, sobretudo sintomas psíquicos.

É possível, assim, estabelecer uma relação acerca do desamparo e do adoecimento: o superego, representante interno do meio social e portador das exigências e ideologias do sistema econômico e político, é a estrutura da personalidade que se manifesta exigindo do ego as requisições do modelo neoliberal, que apresenta ideais quase inatingíveis e culpabiliza unicamente o indivíduo por não atingir esses ideais, ou seja, abandona o indivíduo à própria sorte, deixando-o em situação de desamparo; o superego adquire, assim, um caráter sádico e depressivo, e o ego se vê flagelado, desamparado, condição presente no adoecimento mental.
Portanto, faz-se necessário que a sociedade amplie seu poder de criticidade e passe a valorizar questões fundamentais às relações humanas, perpassando qualquer materialismo ou divergência cultural, no sentido de idealizar e concretizar populações igualitárias, essa que se compreenda a individualidade e a força de uma totalidade social, dando sentido à singularidade de cada ser.

\section{REFERÊNCIAS}

BEYEA, S., NICOLL. L. H. Writing an integrative review. AORN J., v.67. n.4, p. 877-80, 1998.

LANGDON, E. J., WIIK, F. B. Antropologia, saúde e doença: uma introdução ao conceito de cultura aplicado às ciências da saúde. Rev. Latino-Am. Enfermagem, v.18, n.3, p.459-66, 2010.

GEERTZ, C. A interpretação das culturas. Rio de Janeiro: Livros Técnicos e Científicos, 1989.

GEERTZ, C. Nova luz sobre a antropologia. Rio de Janeiro: Jorge Zahar, 2001.

ROBERTSON, R. Globalização: teoria social e cultura global. Petrópolis: Vozes, 2000. 
LARAIA, R. Cultura: um conceito

antropológico. Rio de Janeiro: Zahar, 1986.

FEATHERSTONE, M. O desmanche da cultura: globalização, pós-modernismo e identidade. São Paulo: Studio Nobel, 1997.

BUDO, M. L. D. et al. A cultura permeando os sentimentos e as reações frente à dor. Rev Esc Enferm USP, v.41, n.1, p.36-43, 2007.

SANTOS, B.S. A construção multicultural da igualdade e da diferença. Coimbra: CES, 1999.

FERREIRA FILHA, M. O. et al. A terapia comunitária como estratégia de promoção à saúde mental: o caminho para o empoderamento. Rev. Eletr Enferm., v.11, n.4, p.964-70, 2009.

GUINSBERG, E. La Salud Mental en el Neoliberalismo. México: Plaza y Valdes

Editores, 2001.

LAPLANCHE, J. Pontalis. Vocabulário da

Psicanálise. São Paulo: Martins Fontes, 1983.

MAIA, M. P. S. Um Tapete Vermelho para a Angústia: Clínica Psicanalítica e Contemporaneidade. Rev Psicanálise, v.27, n.4, 2001.
MONTEIRO, C. O Mal-estar Contemporâneo

e a Clínica Psicanalítica. $4^{\circ}$ Encontro

Temático de Psicologia Clínica. Londrina:

Universidade Estadual de Londrina; 2004.

FENICHEL, O. Teoria Psicanalítica das

Neuroses. São Paulo, Rio de Janeiro: Livraria

Atheneu, 1981. 